\title{
Organizational Commitment: Do Employees' Compensations and Benefits Matter?
}

\author{
Mohammad Saidur Rahaman ${ }^{1}$, Mohani Abdul ${ }^{2}$, Mohammad Mizanur Rahman ${ }^{3}$ \\ ${ }^{I}$ (Department of Business Administration, Metropolitan University, Sylhet, Bangladesh) \\ ${ }^{2}$ (Institute for Social Science Studies, Universiti Putra Malaysia. Malaysia) \\ ${ }_{3}^{3}$ (Faculty of Economics and Management, Universiti Putra Malaysia. Malaysia)
}

\begin{abstract}
The main objective of this research is to identify Bangladesh Railway employee's commitment based on compensation and benefits. A structured questionnaire was used to survey the opinions of 40 employees who are from Bangladesh Railway, Rajshahi City. The researchers conducted various statistical analyses such as descriptive statistics, correlation and multiple regression analysis to analyze the survey responses and identified a number of key findings. The study reveals that there are various common factors related to the compensations and benefits that affect employee's commitment.
\end{abstract}

Keywords: Benefit, Commitment, Compensation, Employees' and Organization.

\section{Introduction}

Talented and competent employees are the organization's key resource. The success and failure of any organization largely depend on these employees. So, one of the important and challenging tasks for each organization is to retain its employees. Employee's willingness to stay and commitment on the job largely reckons on compensation and benefits packages of the organization. Organizational commitment is the individual's strong belief and acceptance of the organization's goals and objectives and a strong desire to remain a constituent of the institution. Compensation is output and the benefit that employee receive in the form of pay, wages and also rewards like a monetary exchange for the employee's to increase the performance [1]. Compensation and benefit entail some basic features that tend to make employees satisfy on their job amongst which includes salaries, bonuses, incentives, allowances, promotion, recognition and so on. However, compensation systems continue to increase in scope and administrative complexity and employers have become increasingly interested in benefit cost containment [2].Each of the organizations that have goals to achieve would require satisfied and happy staff in its workforce and Bangladesh Railway is no exception. Bangladesh Railway, a principle transportation agency of the country, is a Government owned and Government managed the organization. It covers a length of $2,877.10$ route kilometers employing a total of 25,083 regular employees. As railway is a very important mode of inland transport, linking the entire length and breadth of the country, its healthy grow naturally contributes to the economic development of the country. For the same purpose the Railway bifurcated into two zones, East \& West, under the administrative control of two general managers, who are accountable to the Director General of Bangladesh Railway. Rajshahi Railway Station is located in Rajshahi, Bangladesh operated by Bangladesh Railway with 6 (six) platforms where approximately 55 employees are employed at this moment. Like other organizations, Bangladesh Railway to take off and achieve its strategic goals would strongly depend on its capacity to attract, retain and maintain competent and satisfied staff into its employment. It could therefore not afford to neglect the need and essentials of workforce satisfaction especially their compensation packages.

\section{Literature Review}

The impact of compensation and benefit on employees' commitment is nowadays considered one of the most important and a controversial issue in modern Human Resource Management. A notable amount of research efforts has been conducted to understand the concepts and to identify implication of organizational employee commitment over the compensation and benefit. Commitment comes into being when a person, by making a side bet, links extraneous interests with a consistent line of activity. It also relates commitment with the nature of the relationship of the member to the system as a whole [3]. Commitment to the willingness of social actors to give their energy and loyalty to social systems, the attachment of personality systems to social relations, who are seen as self-expressive. Commitment to an organization means more than just a formal membership, because it includes attitude and willingness to seek a high level of effort for the organization to achieve organizations goals [4]. The process by which the goals of the organization and those of the individual become increasingly integrated or congruent is commitment [5]. Commitment is that a state of being in which an individual become bound by his action and through these action to beliefs that sustain the activities of his own involvement [6]. Commitment is a psychological state that characterizes the 
employee's relationship with the organization and has implication for the decision to continue membership in the organization [7]. Some researchers suggest that high committed employees may perform better than less committed once [8]. Another researcher suggested that commitment may represent one useful indicator of the effectiveness of an organization [9]. Compensation is a complex topic that has a significant impact on organizational success. Simply compensation is a cost or expenditure as well as an important tool to obtain competitive advantages. Compensation is defined as the total of all rewards provided to employees in return for their service, the overall purposes of which are to attract, retain and motivate employees. According to Robins (1983), Organization compensation can include many different types of rewards and benefits such as salaries, incentive payments and other benefit and services [10]. Compensation is not only the return of benefits but it also reflects on individual's capabilities for organizations [11]. It is the major to attract the employee and motivate the employee to increases the performance [12]. If an employee believes he/she is underpaid, that employee will likely reduce expended effort by working more slowly and being absent [13]. So, compensation effects the employee decision making to stay with their organizations and also accepted the responsibility. The concept of employee compensation and benefits cannot be discussed in a vacuum. The benefit can generate as an important role for employee performance. A good employee feels that value of the company is working for the also enhance the better work they are wellbeing. Benefit programs include social security, workers compensation while discretional programs include health benefits, pension plans, paid time off, tuition reimbursement, recognition award, foreign service premiums, responsibility allowance, child care, on campus accommodation, promotion, annual increment and a host of others researchers mentioned employees' perceptions about their benefits are related to job satisfaction and organizational commitment [14][15][16][17][18].

\section{Theoretical Framework of the Study}

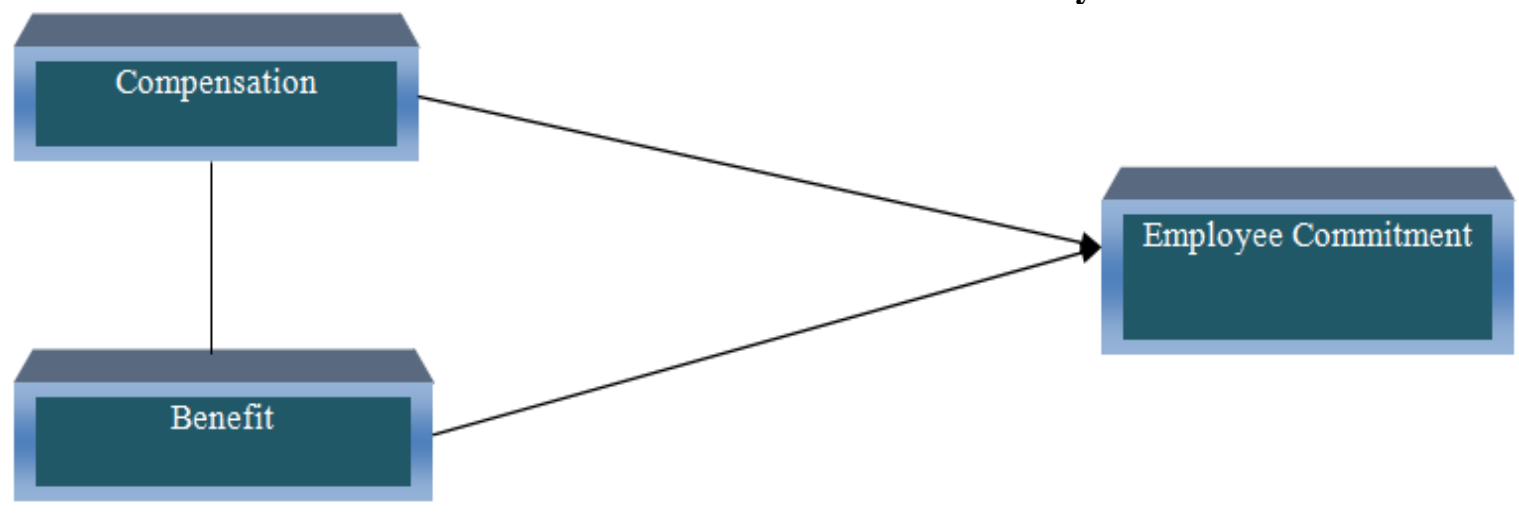

On the basis of previous literature reviews, it is clear that employees' compensation and benefit have a positive impact on employees' commitment. Various studies have established that compensations and benefits are closely related to employees' job satisfaction and job satisfaction can bring about motivation which in turn affects employee job performance and organizational commitment, one company goal to give employees welfare is by providing compensation to retain employees to work. If employees see that hard work and superior performance is recognized and rewarded by the organization, they will increase higher performance with a hope to obtain a higher compensation level. Employee's compensation affects their productivity and their tendency to seek employment to other organization. An effective and appropriate compensation system can help, attract and retain competent and talented individuals who can help the organization accomplish its mission and goals [19]. It is also found that there is a positive and significant relationship between organizational commitment and compensation [20]. Finally it is sought to examine the effect of organizational commitment on employee job Performance and compensation [21].

\section{Research Questions}

On the basis of previous literature reviews and conceptual framework the researchers have found some major research questions which are:

i. What would be the significant impact of compensation on employee's commitment of Bangladesh Railway?

ii. What would be the significant impact of benefit on employee's commitment of Bangladesh Railway?

iii. Is there any significant relationship between compensation and employee's commitment of Bangladesh Railway? 


\section{Objectives of the Study}

The main objective of this research is to identify employee's commitment on compensation and benefit of railway employees in Bangladesh. To emerge the main objective the following subsequent objectives are given below

1. To find out the impact of compensation on employee's commitment.

2. To find out the impact of benefit on employee's commitment.

3. To find out the relationship between compensation and benefit on employee's commitment.

\section{Hypothesis}

$\mathbf{H}_{1} \mathbf{A}$ : Compensation system has a positive impact on employees' commitment (affective, normative and continuous commitment).

$\mathbf{H}_{2} \mathbf{B}$ : Benefits system has a positive impact on employees' commitment (affective, normative and continuous commitment).

\section{Methodology}

The methodology is the roadmap of conducting and completing any research. The present study is a descriptive research used to describe the variables included in the research questionnaire and to describe the internal association among the variables. The study uses different statistical methods like Frequency Distribution, Percentile Distribution, descriptive Statistics, multiple correlations and multiple regression. Malhortra and Peterson (2006) and Zikmund (2003) stated for a research, more accurate data can be generated through the sample size. But sample size can be different according to the different situation. In this research, the researchers have collected the opinions of 40 respondents, all are from Bangladesh Railway, Rajshahi city including male, female, different age group, income and employees types. The questionnaire contains questions of different sections like demographic variables (6), compensation (6) and benefits (6), commitment (18), job satisfaction (6). All the survey questions are scaled on the likert 5-point scale. Here, 1 means strongly disagree whereas 5 means strongly agree. There are 5 sets of questionnaire randomly distributed to the railway employees in Bangladesh. SPSS test is important to ensure the reliability of the survey conducted as well as to improve the questionnaire quality before the actual survey will take place.

\section{Research Model}

Now the researchers have decided to know the significant impact of compensation and benefit on overall employees' commitment. So, the researchers decided to conduct multiple regression analysis. The regression model for the study is as follows-

$\mathrm{EA}=\alpha+\beta 1 \mathrm{X} 1+\beta 2 \mathrm{X} 2+\mathrm{Ct}$

Where,

EA $=$ Employees' commitment (Average of 28 variables)

$\mathrm{X} 1=$ Compensations (Average of Six Factors)

$\mathrm{X} 2=$ Benefits $($ Average of Six Factors $)$

$\mathrm{Et}=$ Error Term

And $\alpha$ is a constant and $\beta 1, \beta 2$, are coefficient to estimate

\section{Empirical Analysis and Results}

The findings are based on the survey. As different employee of Rajshahi railway, provided different opinions regarding the questions so the findings from each non descriptive demographic question are separately explained through charts below-

\section{Percentage Analysis of Demographic Information}

Among 40 participants 35 are male which constitutes $88 \%$ while 5 are female constituting $12 \% .19$ are married which constitutes $47 \%$ while 21 are unmarried constituting $53 \%$. No one is divorced or a widow that is $0 \% .5$ are undergraduate which constitutes $12 \%, 25$ are graduate constituting $63 \%$ and 10 are post graduate constituting $25 \%$. Among 40 participants 3 are managers which constitute $7 \%, 17$ are officers constituting $43 \%$, 16 are academician constituting $40 \%, 4$ participants are from another position constituting $10 \%$ and no one is professional that is $0 \%$. Govt. organization constituting $100 \%$ and no one is from private, semi government or from the autonomous body. So this survey is mainly based on the perception of the employee of government organization. 


\section{Descriptive Statistics}

The descriptive analysis of the data (includes- mean and standard deviation) is given below:

Table 1: Descriptive Statistics

\begin{tabular}{|l|l|l|}
\hline & Mean & Standard Deviation \\
\hline Compensations & 2.92 & 0.91 \\
\hline Benefits & 2.86 & 0.90 \\
\hline Affective Commitment & 3.10 & 0.70 \\
\hline Continuous Commitment & 2.95 & 0.60 \\
\hline Normative Commitment & 3.05 & 0.65 \\
\hline
\end{tabular}

Source: Analyzed by the Author (Using SPSS 14)

The average satisfaction on compensation is 2.92 where in my questionnaire the middle scale was 3. That is most employees are less satisfied with their organization's compensation package. Here, maximum expressed average with the compensation package (Value 3). Standard deviation is 0.91. In terms of benefits most of the employees are less satisfied with their organization's benefits program. Maximum expressed average (average value 2.86), the standard deviation is 0.90.The average affective commitment of employees is 3.10 that are most employees expressed positive and mid level affective commitment with their organization standard deviation is 0.70 .The average continuous commitment of employees is 2.95 where in my questionnaire the middle scale was 3 . That is most employees have a lower continuous commitment with their organization. Standard deviation is 0.60 .On the other hand the average normative commitment of employees is 3.05 that are most employees has a positive normative commitment with their organization. Standard deviation is 0.65 .

\section{Correlation Analysis}

The correlation between commitment (affective, continuous, and normative) and job satisfaction with compensation and benefits program are showing in the table below-

Table 2: Correlation Analysis

\begin{tabular}{|c|c|c|c|c|c|c|}
\hline & $\begin{array}{l}\hat{0} \\
\frac{0}{0} \\
\stackrel{0}{0}\end{array}$ & 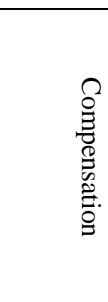 & 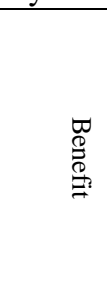 & 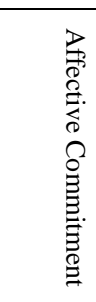 & 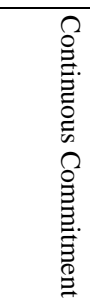 & 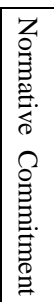 \\
\hline Compensation & & 1 & & & & \\
\hline Benefit & & $0.61 *$ & 1 & & & \\
\hline Affective Commitment & & $0.55^{*}$ & $0.60^{*}$ & 1 & & \\
\hline Continuous Commitment & & $0.31 *$ & $0.45^{*}$ & $0.41 *$ & 1 & \\
\hline Normative Commitment & & $0.24 *$ & $0.26^{*}$ & $0.45^{*}$ & $0.26^{*}$ & 1 \\
\hline
\end{tabular}

Source: Analyzed by the Author (Using SPSS 14)

The correlation between different variables which are statistically significant is briefly discussed below-

\section{- Compensation and Benefit:}

The correlation between compensation and affective commitment is statistically significant at $5 \%$ level. The value is 0.61 which shows higher degree positive correlation. That means If compensation increases then employees benefit also increases.

\section{- Compensation and Affective Commitment:}

The correlation between compensation and affective commitment is statistically significant at $5 \%$ level. The value is 0.55 which shows higher degree positive correlation. That means If compensation increases then employees affective commitment also increases.

\section{- Compensation and Continuous Commitment:}

The correlation between compensation and continuous commitment is positively significant at $5 \%$ level and the value is 0.31 . That means if compensation increases then employees continuous commitment also increases. Employee possesses more continuous commitment with the raise of compensation.

\section{- Compensation and Normative Commitment}

The internal association between compensation and normative commitment is positively significant at $5 \%$ level. The value is 0.24 . That means if compensation increases then employees normative commitment also increases. So it can be said that compensation raise lead to an increase of normative commitment. 


\section{- Benefit and Affective Commitment:}

The internal association between benefit and affective commitment is statistically significant. The association is 0.60 that is a higher degree positive correlation. So it can be said that with the raise of benefit, employees affective commitment also raises. That is benefit lead to affective commitment. More benefitted employees are more affectively committed.

\section{- Benefit and Continuous Commitment:}

The correlation between benefit and continuous commitment is positively significant at $5 \%$ level. The value is 0.45 . That is if benefit raises then employee's continuous commitment raises. So it can be said that increase in benefits leads to increase continuous commitment.

\section{- Benefit and Normative Commitment:}

The correlation between benefit and normative commitment is statistically significant and the value is 0.26 . It means that if benefit increases then employee become more continuously committed toward the organization.

\section{- Affective Commitment and Continuous Commitment:}

The correlation between affective and continuous commitment is positively significant at $5 \%$ level 0.41 . That is an increase in affective commitment also increases continuous commitment. The employee who is more affectively committed also have higher continuous commitment.

\section{- Affective Commitment and Normative Commitment:}

The internal association between affective and normative commitment is statistically significant at $5 \%$ level 0.45 . That is if employee's affective commitment raises his continuous commitment also raises. The association shows a higher positive correlation.

Table 3: Multiple Regression Analysis

Table no 3 A: Multiple Regression Summery

\begin{tabular}{|l|l|l|l|l|}
\hline \multirow{2}{*}{ Model } & $\mathrm{R}$ & R Square & Adjusted R Square & Std. Error of the Estimate \\
\cline { 2 - 5 } & $0.861^{\mathrm{a}}$ & 0.783 & 0.714 & 0.4125 \\
\hline
\end{tabular}

Table 3 B: Analysis of Variance Analysis (ANOVA)

\begin{tabular}{|l|l|l|l|l|l|}
\hline Source of Variation & $(\mathrm{SS})$ & Df & $(\mathrm{MS})$ & Calculated F & P \\
\hline Between Groups & 13.75 & 6 & 2.291 & 4.323 & $0.000 \mathrm{a}$ \\
\hline Within Groups & 17.49 & 33 & 0.530 & & \\
\hline Total & 31.24 & 109 & & & \\
\hline
\end{tabular}

Predictors: $($ Constant $)=$ COM, BEN,

Dependent Variable $=\mathrm{EA}$

Source: Analyzed by the Author (Using SPSS 14)

From the table no 3A, it is seen; there is a significant correlation between independent variables and dependent variable. At $5 \%$ level of significant the correlation is $86.1 \%$. The $\mathrm{R}^{2}$ in the regression model describes the correlation between employee's attitudes and commitment and compensation and benefits .The value of $\mathrm{R}^{2}$ in the table no. 3A indicates $78.3 \%$ of the variation in employee's attitude and commitment can be explained by these studied Compensations and Benefits. Remaining $21.7 \%$ of the variance in attitude and commitment is explained by the variables other than studied variables.

This result also supported by $\mathrm{F}$ test. ANOVA tells us whether the regression equation is explaining a statistically significant portion of the variability in the dependent variable from variability in the independent variables. The $\mathrm{F}$ value in the table no. $3 \mathrm{~B}$ is 4.323 which is higher than the table value of 1.945 . So, the null hypothesis $\left(\mathrm{H}_{0} \mathrm{~A}\right)$ is rejected and hence job related compensations and benefits affect employee's commitment and the P-value $\left(0.000^{\mathrm{a}}\right)$ in the ANOVA test indicates that the result is statistically significant.

Table 4: Coefficients

\begin{tabular}{|l|l|l|l|l|l|l|}
\hline \multirow{2}{*}{ Model } & \multicolumn{4}{|l|}{$\begin{array}{l}\text { Unstandardized } \\
\text { Coefficients }\end{array}$} & \multicolumn{2}{|l|}{ Rank } \\
& Coefficient & Sig. & \\
\cline { 2 - 7 } & $\mathrm{B}$ & Standard Error & Beta & T & Sig. \\
\hline (Constant) & 2.391 & 0.768 & & 2.145 & 0.810 & \\
\hline COM & 0.675 & 0.112 & 0.730 & 3.656 & $0.000^{* *}$ & 1 \\
\hline BEN & 0.546 & 0.108 & 0.644 & 4.790 & $0.000^{* *}$ & 2 \\
\hline
\end{tabular}

Table-4, Coefficient analysis shows the relationship between dependent and each of the independent variable. According to significant values there are some factors which support the hypothesis that means these factors affect employee's commitment. On the basis of t-value, beta value and significance level the following table are designed 
Table 5: Hypotheses Results

\begin{tabular}{|l|l|}
\hline $\begin{array}{l}\mathbf{H}_{1} \mathbf{A}: \text { Compensation system has a positive impact on employees' commitment (affective, normative and continuous } \\
\text { commitment). }\end{array}$ & Accepted \\
\hline $\mathbf{H}_{2} \mathbf{B}$ : Benefit system has a positive impact on employees' commitment (affective, normative and continuous commitment). & Accepted \\
\hline
\end{tabular}

\section{Contribution to Practitioners and Policy Makers}

This study is relevant to the higher authority of Bangladesh Railway as it provides the necessary and real pictures of compensations, benefits and commitment for their employees. The findings could assist managers and higher authority of Bangladesh Railway and policy makers to understand the impact of compensations and benefits on the commitment of employees' of Bangladesh Railway. Additionally, employees of Bangladesh Railway will get a comprehensive idea about compensations, benefits and commitment. Finally, Bangladesh Railway may use necessary information from findings while preparing any policy relating to compensations, benefits and commitment for their employees.

\section{Limitations and Suggestions for Future Research}

This research paper has some mentionable limitations. First, random but convenient sampling technique was used in this study to select employees and Railway (only Rajshahi city) that may limit generalization of commitment of employees of Bangladesh Railway. However, it is noted that in future any researcher may increase the number of respondents and Railway to overcome this limitation. In addition, some of the questionnaires were distributed to the respondents through the managers. Sometimes managers may create pressure employees to complete the questionnaire in a particular way. In this situation actual responses from respondents may not ensure. Although several quantitative types of research have been conducted in this study but it is a matter of considerable issue that qualitative research would further help to contribute to this area to gain insight by looking through different angles of compensations, benefits and commitment. Despite these limitations, the study has provided important findings and contributed significantly to the body of research knowledge regarding compensations, benefits and commitment of employees of Bangladesh Railway.

\section{Conclusion}

Compensation plays an important role in employee's commitment as well as job satisfaction. This study has revealed that the employees of our country are not fully satisfied with the compensation and benefits package and this is affecting their performance, productivity, commitment and loyalty toward the organization. Employees are the valuable asset of any organization and they are the drivers who lead to the ultimate success of the organization. Without their contribution an organization cannot run. So organization needs to pay more attention in designing an effective and attractive compensation package. All efforts must be geared towards developing workers interest in their job so as to make them happy in giving their best to their work, this will ensure industrial harmony. Compensation differential between high and low income earners was related to the low morale, lack of commitment and low productivity. It has been emphasized that compensation must be designed properly as if not careful during design and implementation compensation systems can unintentionally fail to motivate the desired behavior. The results of compensation should include improved employee satisfaction, low employee turnover and better organizational performance. With a highly competitive employment market, employers need to offer their employees a compensation package that would enable them to attract, retain and motivate employees. This study has shown that compensation has a direct influence on employee commitment, performance and productivity. However, this can be achieved if there is transparency in the reward system and if the benefit or compensation meets the aspirations of the beneficiaries. All the research efforts bring to focus how an appropriate reward package can jeer up or influence workers to develop a positive attitude towards their job and thereby increase their productivity. Benefit results in job motivation and satisfaction which ultimately leads to performance.

In conclusion, Organization must ensure that benefits and rewards distributed to employees are dynamic and constantly re-evaluated to ensure their transparency and fairness to all employees so as to continue to have their dedication, commitment and loyalty which are the major drive for keeping contented and satisfied employees thus avoiding turnover but ensuring retention of vibrant employees. Hopefully, the results of this study will enhance the understanding of management on issues bordering on the perception of employees about compensation and help employees in developing policies related to these issues.

\section{References}

[1]. Holt, Devis H, Management: Concept and Practices (New Jersey: Prentice Hall, Englewood Cliffs, 1993).

[2]. Bergmann, T. J., Bergmann M. A., \& Grahn, J. L, How important are employee benefits to public sector employees. Public Personnel Management, 23, 1994, 397-406.

[3]. Grusky, Career mobility and organizational commitment, Administrative Science Quarterly, 10, 1966, 488-503.

[4]. Kanter, R, Evolve. (Boston: Harvard Business School Press, 1968). 
[5]. Hall, D.T., Schneider, B.,\& Nygren, H.T, Personal factors in organizational identification, Administrative Science Quarterly, $15,1970,176-189$.

[6]. Salancik, G.R, Commitment and the control of organizational behavior and belief, New direction for organizational behavior, 1977, $1-54$.

[7]. Meyer \& Allen, Commitment in the workplace, Theory, research and application. (Thousand Oaks, CA: Sage, 1997).

[8]. Mowday, Richard T., Lyman W. Porter, and Robert Dubin, Unit performance, situational factors, and employee attitudes in spatially seperated work units. Organizational Behavior and Human Performance, 12, 1974, 231-248.

[9]. Schein, E, Organizational culture and leadership (San Francisco: Jossey Bass, 1970).

[10]. Robbins SP, Organizational Behavior: Concept, controversies and Application (Prentice Hill, inc, 1983).

[11]. Chang HT, Compensation Related Theories and Model (1996, 371-378).

[12]. Ivancevich, John M. William F. Glueck, Foundations of Personnel/Human Management 21, 1989, $397-409$.

[13]. Byars L, Rue W, Human Resource Management, (Times mirror Higher education Group: Inc company, 1997).

[14]. Cascio, W.F, Managing human resources: Productivity, Quality of work, life, profits (New-York: McGraw Hill Higher Education, 2003).

[15]. Bernadin, H.J, Human resource management: An exponential approach (NewYork: McGraw-Hill Irwin, 2007, 253-277).

[16]. Barber, A. E., Dunham, R. B., \& Formisano, R. A, The impact of flexible benefits on employee satisfaction: A field study. Personnel Psychology, 45, 1992, 55-75.

[17]. Sinclair, R. R., Hannigan, M. A., \& Tetrick, L. E. Benefit coverage and employees' attitudes: A social exchange perspective. Behavioral and social perspectives, 1995,163-185.

[18]. Ward, E. \& Davis, E, Health benefit satisfaction in the public and private sectors: The role of distributive and procedural justice. Public Personnel Management, 24, 1995, 255-271.

[19]. Dessler C, Human Resource Management (Canadian, 2002).

[20]. [Samad, Saminah, The Effects of job Satisfaction on Organizational Commitment and Job Performance Relationship: A Case of Mangers in Malaysia's Manufacturing Companies. European Journal of Social Science. 18(4), 2011

[21]. Khan, M. R. Ziauddin. , Jam,F. A. , Ramay. M. I, The Impact of Organizational Commitment on Employee job Performance. European Journal of Social Science. 15(3), 2010). 